\title{
Emotional and Disclosure Experiences of South African Hiv- Positive Women using Prevention of Mother-To-Child Transmission of Hiv Services
}

\author{
Annie N Mbokane, RN, D Lit et Phil
}

Department of Health Studies,

University of South Africa, Postgraduate student

kayise.mbokane@gmail.com

\section{*Valerie J Ehlers, RN, D Lit et Phil}

Department of Health Studies, University of South Africa, Professor, Pretoria. 0003. South Africa.

ehlersjh@mweb.co.za

\author{
Janetta H Roos, RN, D Lit et Phil
}

Department of Health Studies, University of South Africa, Professor, Pretoria. 0003.

South Africa.

roosjh@unisa.ac.za

\begin{abstract}
Background: When diagnosed HIV-positive women might experience emotional turmoil which could affect their ability to disclose their HIV-positive status to significant others. Unless women manage to disclose their HIV-positive status, their partners/husbands would remain ignorant about this issue and thus unable to provide support to these women. Without their husbands'/partners' support women are unlikely to use condoms consistently while pregnant and breastfeeding, adhere to their anti-retroviral treatment and implement appropriate infant feeding options. These aspects could have detrimental effects on the women's lives and increase the risk of mother-to-child transmission of HIV to their infants.
\end{abstract}

Method: Structured interviews were conducted with 200 women who had used prevention of mother-to-child services in one province of South Africa.

Findings: Almost all women experienced emotional turmoil when learning about their HIV-positive status and were surprised that they tested HIV-positive. Some women took months before disclosing their HIV-positive status to their husbands/partners and a few never did so.

Conclusions: Pre and post-test counselling remain vitally important to help newly diagnosed HIV-positive persons to cope with their emotional experiences and to assist them to disclose their HIV-positive status to significant others, especially to their husbands/partners. Unless prevention of mother-to-child transmission of HIV programmes address the interrelated issues of emotional turmoil and disclosure, the outcomes of these programmes might be jeopardised.

Keywords: Anti-retroviral medicines (ARVs), condom utilisation, disclosure issues, emotional turmoil, Human Immune-Deficiency Virus (HIV), prevention of mother-to-child transmission of HIV (PMTCT)

\author{
Abbreviations \\ AIDS - Auto Immune Deficiency Syndrome \\ $A R V-$ Anti-retroviral \\ ART - Anti-retroviral treatment \\ HCT - HIV counselling and testing \\ HIV - Human Immuno-deficiency Virus \\ MTCT - Mother-to-child transmission \\ PMTCT - Prevention of mother-to-child transmission of HIV
}

\section{INTRODUCTION}

Prevention of mother-to-child transmission of HIV (PMTCT) services are available free of charge to pregnant women in South Africa. However, not all HIV-positive pregnant women use these services, putting their own health and lives at risk as well as increasing the risk of transmitting HIV to their unborn and newly born babies. 
As anti-retrovirals (ARVs) are available free of charge in South Africa, more and more women using ARVs could become pregnant. Although ARVs do not cure HIV, they help to increase the person's CD4 count and decrease the viral load (VL). These aspects decrease the risk of mother-to-child transmission (MTCT) of HIV. Risk reduction can be enhanced by early detection and treatment of opportunistic infections and by attaining the best possible health status during and after pregnancy. Furthermore the HIV-positive woman should consistently use condoms throughout her pregnancy and breastfeeding phases to prevent re-infections as these decrease the CD4 count and increase the VL, increasing the risk of MTCT.

Only pregnant women who use HIV counselling and testing (HCT) services can access and use PMTCT services if they test HIV-positive. Accepting one's HIV-positive status and utilising PMTCT services might pose serious challenges to some pregnant women. Learning about pregnant women's emotional experiences on learning about their HIV-positive status, and their challenges encountered to disclose their HIV-positive status to other persons, might help other women to access and utilise both HCT and PMTCT services in future and to disclose their HIV-positive status to others.

\section{RESEARCH METHODOLOGY}

The study's purpose was to learn about pregnant women's emotional experiences when they tested HIV-positive and about their challenges to disclose their HIV-positive status to other persons. This information could be used to enhance HCT and PMTCT services in future.

A quantitative explorative study was conducted by interviewing 200 women who had used PMTCT services in one district of the Mpumalanga Province in South Africa. The study population comprised all women who had used PMTCT services in the participating district during 2010 and 2011, provided that they could be interviewed either in IsiZulu or in English, were willing to be interviewed. All women (comprising the accessible population) who met the specified inclusive criteria, and who visited well-baby clinics on specific days when research assistants were conducting interviews, were requested to participate in the study. Most women refused and their decisions were respected. By 30 September 2011, when 200 women had been interviewed, data analysis commenced with the assistance of a statistician.

Ten research assistants, who were professional nurses and fluent in both English and IsiZulu, were recruited and trained by the first author to obtain informed consent, conduct structured interviews and record answers correctly. The first author was available at the research sites or by cellular phone in case any emergency arose, but such a situation never occurred. The first author also did spot checks of the completed interview schedules and addressed shortcomings with the relevant research assistant. This was possible because every research assistant had to enter a specific code on every completed interview schedule.

The structured interview schedule comprised sections requesting biographic information, addressing women's emotional experiences after testing HIV-positive, strategies adopted to cope with emotional experiences, whether the interviewees had disclosed their HIV-positive status to others and disclosure-related issues. The instruments were pretested on 10 women who met the inclusive criteria. The interviewed women understood the questions. The structured interviews completed during the pre-test were not analysed as part of the study's data.

The items of the structured interview schedule were selected based on an in-depth literature review and on the South African National Department of Health's guidelines. Every item was judged to be relevant to the research topic by four directors of relevant health programmes in the Mpumalanga Province of South Africa, two nurse researchers and a statistician. Thus face, content and construct validity could be accepted.

There were no dissimilarities between the responses obtained during the pre-test and during the actual data collection phases, implying that the instruments could be accepted as being reliable. No interrater reliability coefficients could be calculated as every woman was only interviewed once. However, no marked differences were detected among documents completed by different research assistants.

The Higher Degrees Committee of the Department of Health Studies of the University of South Africa granted ethical approval that the study could be conducted. The provincial department of health as well as the district health care authorities granted permission for the study to be conducted. The manager of every participating clinic provided a private room for conducting interviews, consented 
that interviews could be conducted. Great care was taken to ensure that no woman lost her place in the clinic queue due to being interviewed. All women attending a clinic on a specific day were invited to participate. Most women refused and their decisions were respected. Anonymity was guaranteed as only numbers (001-200) were used on the completed interview schedules without any identifying information. Confidentiality was guaranteed as each interview was conducted in a private room and every woman was assured that her name would never be used in any research report. Every research assistant signed a confidentiality report with the first author.

The women were not paid for being interviewed, but the potential future benefit of sharing their experiences was explained. All ethical principles were observed. No harm was caused as only interviews were conducted. However, the first author was accessible in case any woman required assistance of referral to a specific health care worker, but this never proved necessary.

In response to some sub-sections of the structured interview schedule, respondents could select various relevant answers, implying that the total number of responses to items in a sub-section of the instrument might exceed the total number of women $(\mathrm{N}=200)$ who were interviewed. However, the percentages for responses to individual items were calculated out of 200 as every respondent could have selected each response.

\section{RESUlts AND Discussion}

Respondents were questioned about their experiences after testing HIV-positive, how they perceived their HIV-positive status, and how they experienced specific HIV-positive status-related issues. Disclosing of their HIV-positive status to others was also addressed as non-disclosure or limited disclosure could affect the outcomes of the PMTCT programme adversely.

Most respondents (88.5\%; $\mathrm{n}=177$ ) reported learning about their HIV-positive results as being a challenge not only during their current but also during their future pregnancies. This finding is supported by Avert (2013) who explained that an HIV-positive diagnosis can cause numerous emotions, making it difficult for the person to decide how to react. Some of the current study's respondents $(60.0 \% ; n=120)$ were surprised by their HIV-positive results and $44.0 \%(n=88)$ were scared, 33.5\% $(n=69)$ were confused, $30.6 \%(n=67)$ felt hopeless, $27.5 \%(n=55)$ were angry, $19.0 \%$ $(n=38)$ experienced resentment, $18.5 \%(n=37)$ were depressed, $17.5 \%(n=35)$ were anxious, and $8.5 \%$ $(\mathrm{n}=17)$ felt lost.

Avert (2013) stated “... anger is a powerful emotion that could be used by an anxious person as a coping strategy to feel powerful in a powerless situation. Resentment could be towards the individual herself for her own and/or her partner's infidelity or to the person she suspected infected her". Respondents' anxiety relate to fear of changes in their lives, including discrimination and ostracism. Anxiety and depression could cause “...changes in appetite, restlessness, suicidal ideas, tiredness and insomnia, which could impact negatively on the woman's health and on the well-being of her unborn child. Being diagnosed HIV-positive could lead to feeling a loss of one's independence, health and usual sexual activities” (Avert 2013).

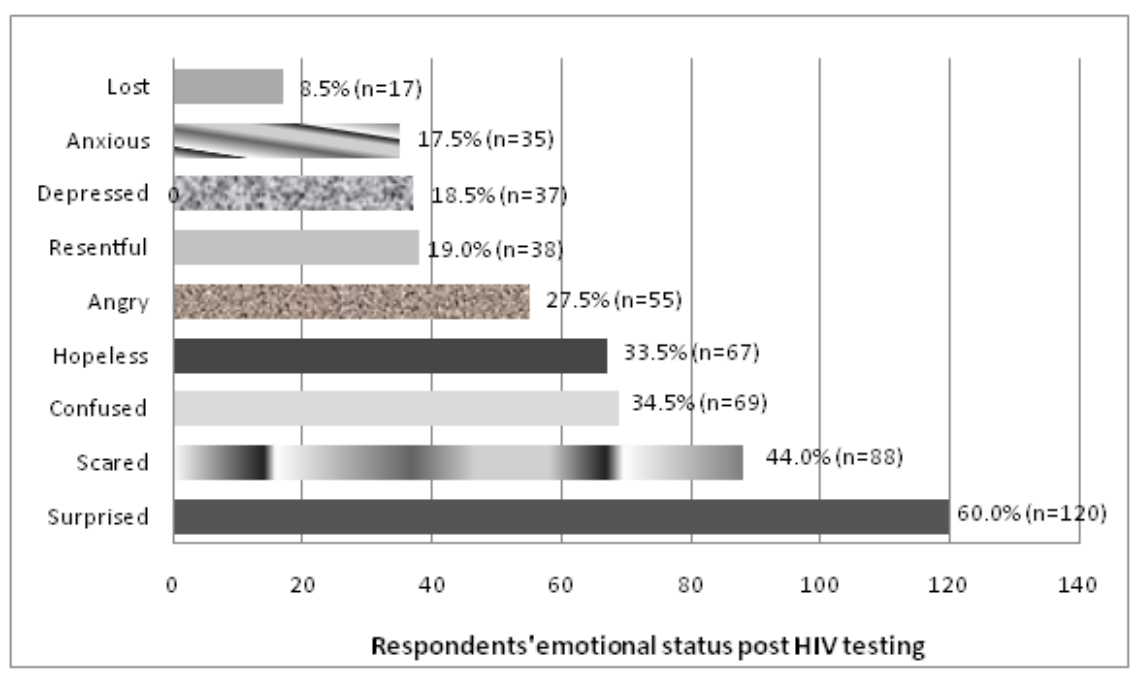

Figure1. Respondents' emotional status after testing HIV-positive 


\section{Reasons why respondents experienced emotional turmoil}

Almost all respondents (92.0\%; $\mathrm{n}=184)$ reported being shocked because they were diagnosed HIVpositive, $47.0 \%(n=94)$ feared death, whilst $38.5 \%(n=77)$ only had sexual intercourse with their partners/husbands. Some respondents might have felt betrayed because they trusted their partners (25.0\%; $n=50)$; some were fearful about their babies' futures (23.5\%; $n=47)$, some feared that their partners might abandon them $(12.5 \%$; $n=25)$, and $18.0 \%(n=36)$ knew that their husbands/partners had more than one sex partner.

All interviewed women (100.0\%; $\mathrm{N}=200)$ had used PMTCT services and were pregnant as a result of not using condoms effectively. Consequently, it could not be explained why $92.0 \%(n=184)$ of the respondents were surprised to be HIV-positive. Of the respondents $25.0 \%(n=50)$ believed that they were protected from becoming infected with HIV because they were faithful to one partner. Rujumba, Neema, Tumwine, Tylleskar and Heggenhougen (2013:10) also reported that some women believed being faithful to one sex partner prevented them from becoming HIV-positive. Women holding such false perceptions of safety might not use condoms, risking both HIV infection and MTCT. These women might have experienced life as being unjust because they only had one sex partner as reported by other researchers (Avert 2013; Fabianova 2011:188).

However, not all interviewed women experienced negative emotions on hearing their HIV-positive status as 23 respondents indicated that this was not a difficult experience. Some $(43.5 \% ; n=10)$ said that they at least knew their HIV status, $13.0 \%(n=3)$ believed that HIV treatment was going to help them to cope, $21.7 \%(n=5)$ indicated that other people coped with HIV, and $21.7 \%(n=5)$ simply had to accept what could not be changed.

\section{Disclosure}

A pregnant woman's emotional experiences could influence whether or not she would disclose her HIV-positive status to others, when she would do so and to how many people. Disclosure forms an integral part of PMTCT programmes because the HIV-positive pregnant woman requires her partner's cooperation to use condoms effectively, take her ARVs regularly, attend relevant clinics and adhere to an appropriate infant feeding option.

Out of the current study's 200 respondents, $12.0 \%(\mathrm{n}=24)$ did not agree that it was good to disclose one's HIV-positive status to other persons. Out of 176 respondents, $44.9 \%(n=79)$ disclosed their HIV-positive status only to one person, while $19.9 \%(n=35)$ did so to two persons, $13.6 \%(n=24)$ to three persons, $9.7 \%(n=17)$ to four persons, and $11.9 \%(n=21)$ to five persons. Madiba and Letsoalo (2013:8) indicated that disclosure could lead to discrimination, stigma and isolation, but it could not be determined from the current study's findings whether or not the respondents encountered any of these experiences. On the other hand, disclosure could help to break down the silence surrounding sex issues and HIV stigma (Maman, Van Rooyen \& Groves 2013:229), when many people in specific communities disclose their HIV-positive status.

The current study's 176 respondents revealed that some $(65.3 \% \mathrm{n}=115)$ disclosed their HIV-positive status within one week after their HIV-positive diagnosis, some $(21.6 \%$; $n=38)$ did so within one month of their diagnosis, status, a few $(8.0 \%$; $n=14)$ waited six months before disclosure, and $5.1 \%$ $(n=9)$ only did so after a year. As many as $12.0 \%(n=24)$ of the current study's respondents had never disclosed their HIV-positive status to others even though these interviews were conducted 6-14 weeks after their babies' births. This finding implies that some women who used PMTCT services had to cope without any support as their significant others were unaware of their HIV-positive status and thus also of their utilisation of PMTCT services.

As many as $70.5 \%(n=124)$ of the respondents disclosed their HIV-positive status first to their partners, $43.8 \%(n=77)$ did so to their parents, $25.0 \%(n=44)$ to their sisters, and $20.5 \%(n=36)$ to their friends. However, $8.0 \%(\mathrm{n}=14)$ of the HIV-positive women initially disclosed to their brothers, $5.1 \%$ $(\mathrm{n}=9)$ to unspecified relatives and $1.7 \%(\mathrm{n}=3)$ to their mothers-in-law.

Madiba and Letsoalo (2013:8) indicated that HIV-positive women's socio-economic status could influence their disclosure of their HIV-positive status. In the current study, 70.5\% $(n=124)$ out of the 176 women who had disclosed their HIV-positive status to others, had initially disclosed to their partners. However, 78\% (156 out of 200) of the current study's respondents were unemployed, and out of the 44 working women, $50.0 \%(n=22)$ earned less than R1 000 (approximately USD 426) per 
month, implying that they were financially dependent on others. However, $76.5 \%(n=153)$ out of the 200 respondents had acquired at least eight years' schooling, which might have enabled them to disclose their HIV-positive status. Those 176 (88.0\%) respondents who believed that it was advantageous to disclose their HIV-positive status, stipulated the following reasons for their beliefs:

- $34.7 \%(n=61)$ felt less stressed

- $29.0 \%(\mathrm{n}=51)$ felt free

- $40.0 \%(\mathrm{n}=70)$ obtained the required support after disclosure

- $15.3 \%(\mathrm{n}=27)$ acquired advice

- $11.4 \%(\mathrm{n}=20)$ felt one could not hide one’s HIV-positive status

- $16.5 \%(n=29)$ wanted people to know what was wrong with them in case they became ill, and

- $22.2 \%(n=39)$ disclosed to encourage other people to undergo HIV testing.

These findings seem to agree with those of Maman et al (2013:229) who reported that the women who participated in their study, felt as if “... a heavy load had been removed from their shoulders, and that they felt free and relieved to live their lives after having disclosed their HIV-positive status to others".

Table1. Respondents' reasons for disclosing their HIV-positive status ( $n=176)$

\begin{tabular}{|l|l|l|}
\hline $\begin{array}{l}\text { RESPONDENTS' REASONS FOR DISCLOSING THEIR HIV- } \\
\text { POSITIVE STATUS }\end{array}$ & FREQUENCY & PERCENTAGE \\
\hline Once you disclose your status you get the required support & 70 & 40.0 \\
\hline When you disclose your HIV status you feel less stressed & 61 & 34.7 \\
\hline When you disclose your HIV-positive status you feel free & 51 & 29.0 \\
\hline $\begin{array}{l}\text { By disclosing your HIV status you encourage other people to undergo } \\
\text { HIV testing }\end{array}$ & 39 & 22.2 \\
\hline $\begin{array}{l}\text { If you disclose, when you are sick people will know what is wrong } \\
\text { with you }\end{array}$ & 29 & 16.5 \\
\hline During disclosure one is able to get advice & 27 & 15.3 \\
\hline An HIV-positive status cannot be hidden & 20 & 11.4 \\
\hline
\end{tabular}

Madiba and Letsoalo's (2013:8) findings reported that women disclosed their HIV-positive status to receive emotional support, similar to the current study's findings. Shiyoleni (2013:10) found that disclosure could help to break down HIV stigma as more people use HCT services. In the current study, $17.8 \%(n=39)$ of the women disclosed their HIV-positive status to encourage their partners to get tested.

Out of the current study's 200 respondents, 24.5\% ( $\mathrm{n}=49)$ disagreed that communities discriminated against HIV-positive persons as $26.5 \%(\mathrm{n}=13)$ indicated that communities were knowledgeable about HIV, 49.0\% ( $n=24)$ thought people understood HIV, and 24.5\% $(n=12)$ said societies could not discriminate against all the HIV-positive persons as many people were HIV-positive. These responses differ from those reported by Le Roux Kemp (2013:202) that HIV causes societies to “... distance themselves from the disease and from people suffering from a long term illness".

\section{Reasons why some respondents did not disclose their HIV-positive status}

Only 12.0\% ( $\mathrm{n}=24)$ of the 200 interviewed women never disclosed their HIV-positive status to others. As many as $33.3 \%(n=8)$ of these women maintained that other people gossiped about HIV-positive individuals, 37.5\% ( $\mathrm{n}=9)$ regarded people as being untrustworthy, and 29.2\% $(\mathrm{n}=7)$ feared discrimination. Madiba and Letsoalo (2013:8) maintained that some HIV-positive individuals might not disclose their HIV-positive status if they do not expect support from others.

When asked why the respondents believed that societies discriminated against HIV-positive individuals, 52.3\% ( $\mathrm{n}=79)$ indicated that societies lacked HIV-related information, 15.2\% $(\mathrm{n}=23)$ said some people failed to realise that anyone could become HIV-positive, $4.6 \%(n=7)$ said people hated HIV-positive individuals, whilst $4.6 \%(n=7)$ felt that HIV-positive persons were considered to be useless by societies. Only $6.6 \%(n=10)$ of the interviewed women in the current study reported that some society members regarded HIV to be a death sentence, 9.3\% $(\mathrm{n}=14)$ believed people gossiped 
about HIV-positive individuals and 7.3\% $(\mathrm{n}=11)$ indicated that HIV had been called many different names in societies.

\section{CONCLUSIONS AND RECOMMENDATIONS}

In order to avoid repetitions, every conclusion will be followed by a relevant recommendation.

As many as $88.5 \%$ ( $\mathrm{n}=177)$ of the respondents experienced emotional turmoil on being diagnosed HIV-positive. This finding emphasises the dire necessity of providing effective counselling before and after testing any person for HIV, as specified in the guidelines of the National Department of Health of South Africa (NDOH 2010, 2013).

Most (92.0\%; $n=184)$ women were shocked to be diagnosed HIV-positive. As all respondents became pregnant because they did not use condoms effectively, and probably also became infected with HIV because they did not use condoms effectively, health education should focus on the dire necessity to use condoms effectively and consistently, even with regular and exclusive sex partners. Health education should be consistent for all population groups but should focus specifically on girls and young women and on women attending family planning clinics. Consistent condom use throughout pregnancy and breastfeeding phases is essential to prevent re-infections which could cause the CD4 count to fall and the viral load to rise, increasing the risk of MTCT. The outcomes of PMTCT programmes could be jeopardised if women fail to use condoms effectively while pregnant and breastfeeding and this health education message needs to be emphasised consistently.

Some respondents $(25.0 \% \%$; $n=50)$ considered themselves to be protected from HIV infection because they only had sex with one partner. It seems vitally important that health education messages should emphasise that 'being faithful' only offers protection against HIV infection if both partners are exclusively faithful to each other and if both partners are HIV-negative. If one partner is HIVpositive, 'being faithful' to this partner could indeed cause an HIV infection unless condoms are used effectively at every occasion. Even if both partners are HIV-positive, condoms should be used consistently to prevent re-infections.

The outcomes of PMTCT programmes could be compromised by ineffective condom use. Both men and women should realise, as a result of sustained health education, that re-infection can cause an HIV-positive woman's CD4 count to fall and viral load to rise, increasing the MTCT risk during pregnancy and breastfeeding.

Women need to disclose their HIV-positive status to their husbands/partners to obtain their cooperation to use condoms effectively, but not all respondents did so. Disclosure of a woman's HIV-positive status could be adversely affected by her emotional turmoil when diagnosed HIVpositive. Thus post-test counselling should assist women to cope with their emotional experiences and to disclose their HIV-positive status to their husbands/partners as soon as possible. Without such disclosure, HIV-positive women's husbands/partners cannot support them to utilise free PMTCT services effectively. PMTCT services should offer opportunities for couples to be tested and counselled if couples should prefer this. HCT for couples might facilitate sharing of the information and both partners will be knowledgeable about each other's HIV status.

Helping newly diagnosed HIV-positive persons to cope with their emotional turmoil and to disclose their HIV-positive status to significant other persons, could enhance the outcomes of PMTCT programmes. This is the case because these women would be more likely to use condoms effectively (especially while pregnant and breastfeeding), adhere to appropriate infant feeding options, take their ARVs as prescribed and attend the relevant clinics regularly. Women whose husbands/partners are unaware of their HIV-positive status could encounter daily challenges to adhere to the PMTCT programme's requirements, adversely affecting their own health and increasing the risk of MTCT for their infants. Thus helping HIV-positive women to cope with emotional issues and to disclose their HIV-positive status to their husbands/partners is an integral part of the PMTCT strategy.

\section{LIMITATIONS OF THE STUDY}

Structured interviews were conducted with 200 women from one district in one province of South Africa. Thus the findings cannot be generalised to the entire country, unless more studies are conducted in different parts of the country. Richer information could be obtained by conducting indepth qualitative interviews with women using PMTCT services. 
This study focussed only on the experiences of women. Future studies should focus on men's emotional experiences and disclosure issues after being diagnosed HIV-positive.

\section{REFERENCES}

[1] Avert. 2013. Preventing mother-to-child Transmission (PMTCT) in practice.

[2] (http://www.avert.org/preventing-mother-child-transmission-pmtct-practice.htm) (accessed 22 March 2013).

[3] Fabianova, L. 2011. Psychosocial aspects of people living with HIV/AIDS. From: http://cdn.in techopen.com/pdfs-wm/22550.pdf (accessed 02 January 2014).

[4] Le Roux-Kemp, A. 2013. To disclose or not to disclose: that is a question. (http://www.saflii .org/za/journals/PER/2013/7.html) (accessed 10 November 2013).

[5] Madiba, S \& Latsaolo, R. 2013. HIV disclosure to partners and family among women enrolled in a prevention of mother-to-child transmission of HIV program: implications for infant feeding in poor resourced communities in South Africa. Global Journal of Health Science 5(4):1-13.

[6] Maman, S, Van Rooyen, H \& Groves, AK. 2013. HIV status disclosure to families for social support in South Africa From: http://www.cbvct.med.ucla.edu/pubs/maman2013.pdf (accessed 14 November 2014).

[7] National Department of Health., 2010. Policy and guidelines for the implementation of the PMTCT programme. Pretoria: Government Printer.

[8] National Department of Health., 2013. The South African antiretroviral treatment guidelines. Pretoria: Government Printer.

[9] Rujumba J, Neema S, Tumwine, JK, Tylleskar T \& Heggenhougen HK. 2013. Pregnant women's experiences of routine counselling and testing for HIV in Eastern Uganda:a qualitative study. BioMed Central Health Services Research. From: http://www.biomedcentral.com/14726963/13/189 (accessed 14 January 2014).

[10] Shiyoleni, MN. 2013. Non-disclosure of HIV serostatus to partners among HIV positive pregnant women enrolled on the prevention of mother to child transmission (PMTCT) programme at Katutura antenatal clinic, Windhoek, Namibia. Stellenbosch University. From: https://scholar.sun.ac.za/bitstream/handle/10019.1/79858/shiyoleni_nondisclosure_2013.pdf?seq uence $=2$ (accessed 11 May 2013).

[11] World Health Organization., 2013. Consolidated guidelines on the use of antiretroviral drugs for treating and preventing HIV infection. (http://www.who.int/hiv/pub/guidelines/arv2013/ download/en) (accessed 13 March 2014). 